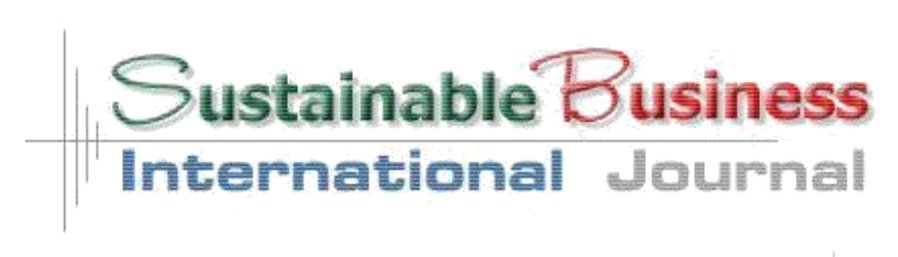

SBIJ86 - JUNHO DE 2019 - ISSN 1807-5908

\title{
UM ESTUDO SOBRE AS CARACTERÍSTICAS DOS SISTEMAS DE CONTROLE GERENCIAL EM INSTITUIÇÕES BRASILEIRAS DE SAÚDE PÚBLICA
}

\section{A STUDY ON THE CHARACTERISTICS OF MANAGEMENT CONTROL SYSTEMS IN BRAZILIAN PUBLIC HEALTH INSTITUTIONS}

\section{Luiz Claudio de Camargo Moureau Linhares luizmoureau@yahoo.com.br Unigranrio - R.J}

Josir Simeone Gomes

josirsgomes@gmail.com

Unigranrio - R.J

11 Contextus ISSN 1807-5908

Avaliação: Double Blind Review

Submissão em 30/09/2018.

Aceito em 15/10/2018. 


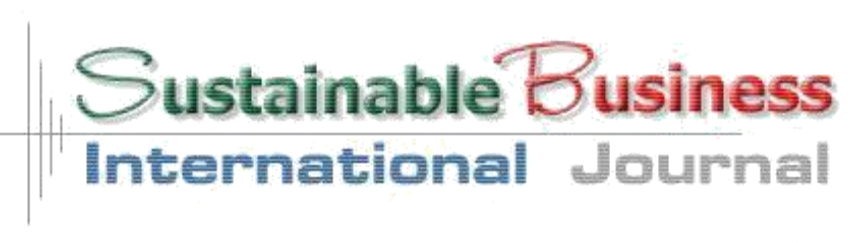

SBIJ86 - JUNHO DE 2019 - ISSN 1807-5908

\title{
Resumo:
}

Este artigo tem por finalidade propor a operacionalização e orientação para pesquisas sobre sistemas de controle gerencial (SCG) em organizações não vocacionadas ao lucro, em especial para as instituições brasileiras de saúde pública. Para operacionalizar a pesquisa, foram propostas 05 variáveis, através do método de estudo de caso, com referencial teórico construído em execução do orçamento público, contratação pública e controle gerencial em organizações sem fins lucrativos. A pesquisa se materializará através de entrevista com atores relevantes da área de gestão da entidade a ser investigada, auxiliada por questionários com perguntas pertinentes para cada uma das variáveis propostas e da análise em documentos institucionais. As respostas e os achados poderão ser sistematizados, o que facilitará posteriores análises de dados e as conclusões resultantes. Conclui-se que esta proposição de operacionalização de pesquisa, contribuirá para um melhor conhecimento sobre os sistemas de controle gerencial em saúde pública e para futuros estudos sobre o tema, ao permitir a comparabilidade dos resultados alcançados com o encontrado na literatura que versa sobre o tema. Recomenda-se, se necessário, a concessão de outras variáveis, conforme a especificidade dos SCG da instituição de saúde pública a ser pesquisada.

Palavras chave: Planejamento; Controle Gerencial; Orçamento; Administração Pública.

\begin{abstract}
:
This article aims at proposing the operationalization and orientation for research on management control systems (MCS) in nonprofit organizations, especially for Brazilian public health institutions. In order to operationalize the research, 05 variables were proposed, through the case study method, with theoretical reference built on public budget execution, public contracting and managerial control in non-profit organizations. The research will materialize through an interview with relevant stakeholders in the area of management of the entity to be investigated, aided by questionnaires with pertinent questions for each of the proposed variables and analysis in institutional documents. Responses and findings can be systematized, which will facilitate further analysis of data and the resulting conclusions. It is concluded that this proposition of research operation, will contribute to a better knowledge about the systems of management control in public health and future studies on the subject, allowing the comparability of the results achieved with that found in the literature that deals with the theme. It is recommended, if necessary, the granting of other variables, according to the specificity of the SCGs of the public health institution to be researched.
\end{abstract}

Key words: Planning; Management Control; Budget; Public Administration. 


\section{Sustainable Business \\ International Joumal}

SBIJ86 - JUNHO DE 2019 - ISSN 1807-5908

\section{INTRODUÇÃO}

O crescimento dos custos operacionais e a contingência recorrente de recursos governamentais é motivo de preocupação por parte da gestão pública. A opinião pública brasileira, geralmente insiste em cobrar uma diminuição da máquina estatal, concomitante com a melhoria dos serviços prestados pelo governo, especialmente na saúde pública. Consta na constituição brasileira que é um dever de Estado, que o direito igualitário à promoção, proteção e recuperação da saúde dos cidadãos, devendo ser realizado através de ações e políticas econômicas e sociais (DO BRASIL, 2018).

A gestão pública orientada para resultados indica a necessidade de institucionalização das atividades de controle e planejamento, onde aspectos financeiros e qualitativos da gestão devam ser considerados na avaliação do desempenho da gestão pública. Para isso, se tem o imperativo de um controle eficiente e eficaz sobre as despesas dos recursos de sua organização (QUINTAL et al, 2012; GRATERON, 1999).

Define-se com controle gerencial, como o processo no qual os administradores se asseguram que as utilizações dos recursos organizacionais possam atingir os objetivos organizacionais planejados e se estão atendendo as expectativas dos membros da organização. Sistemas de Controle Gerencial (SCG) são instrumentos, meio e mecanismos que buscam verificar a eficiência e eficácia quanto à utilização dos recursos e os resultados obtidos. A atual conotação distinguiu e situou controle gerencial em uma posição intermediária, entre o planejamento estratégico e o controle operacional da organização (ANTHONY; GOVINDARAJAN, 2008; OTLEY, 1994). 


\section{Sustainable Business \\ International Journal}

SBIJ86 - JUNHO DE 2019 - ISSN 1807-5908

Para que um controle gerencial das entidades públicas auxilie o processo decisório dos diretores, remete para uma institucionalização de desenvolvimento e manutenção de sistemas de controle gerencial, a fim de estabelecer condições necessárias para minimização de risco de controle e as ações de correição. Um ambiente de controle na administração pública, que vise ser efetivo no cumprimento de sua missão deve considerar as seguintes áreas numa entidade: Planejamento; Execução orçamentária; Gestão de pessoal; e Sistema de informações contábil-gerencial (RIBEIRO et al, 2008).

Admitindo que as entidades públicas tenham a necessidade de uma administração eficiente e eficaz sobre as utilizações de seus principais recursos organizacionais (pessoal, despesas de custeio e investimentos), percebe-se que o número de pesquisas que abordam os sistemas de controle gerencial na administração pública brasileira ainda é incipiente, onde aponta a necessidade da condução de mais estudos exploratórios nesse setor.

Sob esta ótica, este artigo sugere uma construção referencial teórica em execução do orçamento público, contratação pública e controle gerencial em organizações públicas, de maneira a subsidiar a proposição de variáveis que auxiliarão operacionalizar e nortear futuras pesquisas em sistemas de controle gerencial em instituições brasileiras de saúde pública, quanto à avaliação de como se aproximam ou se afastam dos conceitos encontrados nas literaturas que versam sobre o tema.

\section{REFERENCIAL PROPOSTO}

\subsection{Execução do orçamento público}

O Plano Plurianual (metas de longo prazo), passando pela Lei de Diretrizes Orçamentárias (metas anuais) e o Orçamento Anual, (recursos orçamentários alocados para a 


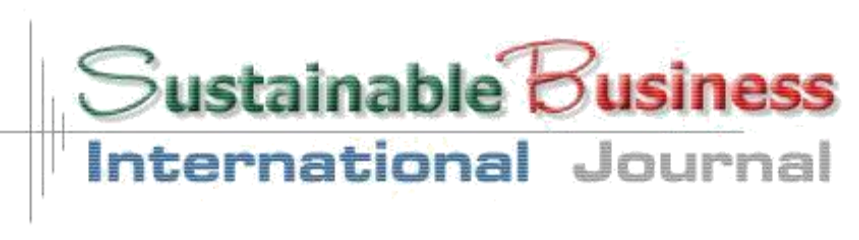

SBIJ86 - JUNHO DE 2019 - ISSN 1807-5908

realização das metas anuais), são instrumentos de planejamento em relação à aplicação dos recursos públicos brasileiros. Embora essa tríade se baseie num sistema que integra o planejamento e orçamento, seja o mais avançado em programação dos gastos públicos, há uma percepção de que há falta de planejamento e controle no Brasil, pois seus objetivos ficam distorcidos diante do afastamento entre o orçamento planejado e o executado (PELLINI, 2003; PARES; VALLE, 2006).

A Constituição federal diz que não há despesa que não esteja autorizada na lei orçamentária anual, através do equilíbrio entre receitas e despesas, não se permitindo ao governo buscar receitas de modo indefinido, sem qualquer correspondência com suas necessidades. O orçamento das entidades da administração indireta deixou de constar sob a forma de dotações globais e a lei orçamentária passou a ser composta de três orçamentos: o fiscal, o de investimento das empresas e o da seguridade social, passando a subordinar-se a lei de diretrizes orçamentárias e do plano plurianual (PINTO, 2006; SANCHES, 1995).

A contabilidade de custos tradicionalmente tem depositado uma demarcação relativamente simples entre os conceitos custo e despesa no âmbito empresarial. Os Custos de produção são gastos acontecidos no produto pronto até o momento da venda, já as despesas são gastos advindos a partir do momento da venda, com sua comercialização, onde impactam o resultado do período. Na administração pública, as despesas orçamentárias têm um circuito próprio, em que são fixadas, empenhadas, liquidadas e pagas (MACHADO; HOLANDA, 2010).

A despesa orçamentária liquidada é onde começa a construção do sistema de informações dos custos públicos. Quando é relativa aos bens ou serviços utilizados e consumidos no exercício ou ano corrente, conceitua-se como custo e quando beneficiar 


\section{Sustainablé Business \\ International Joumal}

SBIJ86 - JUNHO DE 2019 - ISSN 1807-5908

exercícios ou anos futuros será conceituado como investimento. A despesa liquidada é considerada como um elo conceitual e metodológico para apuração dos custos e efetiva aplicação dos recursos no setor público brasileiro, estabelecendo assim a disposição das despesas orçamentárias por categorias econômicas (MACHADO; HOLANDA, 2010).

\subsection{Contratação pública}

As contratações da administração pública brasileira, que envolvem as tarefas e os respectivos processos para adquirir bens, serviços e obras de engenharia, se apoiam em uma estrutura de leis e normativas, estrutura organizacional, pessoas, orçamento, execução financeira, além de um conjunto de métodos e instrumentos específicos. Sugerem um continuado relacionamento com o mercado fornecedor de bens e serviços e com a sociedade, na forma de acordos comerciais, sendo elemento de demandas e atenção de todos (FERNANDES, 2016).

Os gestores públicos carecem de distintas informações gerenciais que sejam adequadas para auxiliar nas suas deliberações entre comprar ou alugar, terceirizar determinado serviço ou produzir internamente, ou mesmo comparar os custos, atividades e serviços semelhantes produzidos por outros órgãos públicos. Todo comprometimento da gestão que vise aperfeiçoar a qualidade dos gastos públicos, em especial com as aquisições e contratação de bens e serviços são fundamentais, haja vista que tais gastos representam considerável percentual dos orçamentos das unidades de governo, onde demandam abrangente capacidade de gestão e monitoramento (VAZ; LOTTA, 2011; MACHADO; HOLANDA, 2010; TRIDAPALLI; FERNANDES; MACHADO, 2009). 


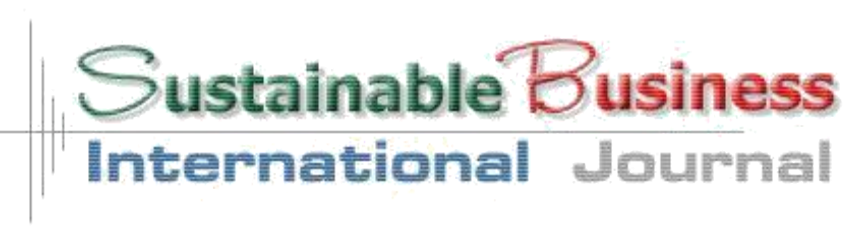

SBIJ86 - JUNHO DE 2019 - ISSN 1807-5908

Após a definição dos bens e serviços que serão contratados, o processo de contratação pública para ser eficiente e eficaz, deve ser elaborado através de um plano de gerenciamento que subsidiará a elaboração contratual, onde se detalhará as metas quantitativas imprescindíveis, visando o alcance das metas e dos serviços que serão executados, com a definição do método de cálculo, a validação dos indicadores de qualidade, indicadores gerenciais e modelos de relatórios com as informações indispensáveis para o acompanhamento e o monitoramento do contrato, sempre em conformidade com a legislação (DOS SANTOS, 2014).

\subsection{Controle Gerencial em organizações não vocacionadas ao lucro}

O processo de controle gerencial acontece no contexto dos objetivos organizacionais e das estratégias que a alta administração elegeu para alcançá-las. Ampla parte do processo de controle gerencial é informal, acontecem por conversas, memorandos, reuniões e até mesmo por expressões faciais, ou seja, são dispositivos de controle que não são passíveis de sistematização. Os conceitos basais de controle gerencial são os mesmos em organizações com ou sem fins lucrativos, mas por causa das características especiais de organizações não vocacionadas ao lucro, a maneira como os gestores cultivam esses conceitos diferirá em aspectos importantes. $\mathrm{O}$ processo formal de controle gerencial tem quatro fases principais: (1) Planejamento estratégico (também chamado de programação); (2) Preparação do orçamento; (3) Operação e medição; e (4) Relatórios e avaliação (Anthony \& Young, 2003).

\subsubsection{A Abordagem de Hofstede}

Hofstede (1981) diz que o controle de gestão das organizações públicas tem que ser na esfera das "atividades", em vez da esfera das "organizações", ou seja, as atividades públicas, não produtivas, sem fins lucrativos e indiretos, de um ponto de vista de controle de gestão são 


\section{Sustainable Business \\ International Joumal}

SBIJ86 - JUNHO DE 2019 - ISSN 1807-5908

as atividades exercidas pelos responsáveis e as ferramentas disponíveis para assegurar que esses recursos sejam obtidos e empregados de forma efetiva e eficientemente na realização dos objetivos organizacionais. As distinções usuais entre organizações públicas, privadas e voluntárias ou entre organizações de produção, serviços e vendas não são muito significativas do ponto de vista do controle gerencial. Os quatro critérios de atividades devem ser considerados:

I. Os objetivos são não ambíguos ou ambíguos?

Este é o critério mais importante para o controle de gestão. O controle implica um alvo, e quando não há um alvo claro, os objetivos são dúbios. Os objetivos não são ambíguos quando há consenso entre os componentes da organização, ou quando eles podem ser impostos por uma autoridade central ou uma coalizão mais influente.

II. Os resultados são mensuráveis ou não mensuráveis?

O controle gerencial implica que o resultado de uma atividade pode ser identificado e cotejado com os objetivos organizacionais definidos, todavia diversas atividades nas organizações públicas determinam resultados qualitativos e vagos. Como quantificar a produção das forças armadas quando não há guerra? Nestes casos, apenas os recursos alocados para a atividade (entradas) podem ser mensuradas, já as saídas não podem.

III. Os efeitos das intervenções de gestão são conhecidos ou desconhecidos?

A efetividade do controle gerencial sugere que os esforços alocados para uma atividade, podem ser redirecionados, no caso dos resultados não atingirem os objetivos instituídos, isso implica que o administrador sabe como interferir para obter a conformidade almejada e as relações entre sua ingerência, a reação da organização e a resposta do meio ambiente devem ser transparentes. 


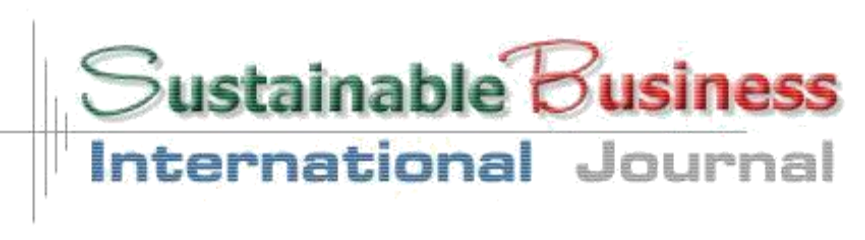

SBIJ86 - JUNHO DE 2019 - ISSN 1807-5908

IV. A atividade é repetitiva ou não repetitiva?

As atividades que acontecem diariamente, semanalmente, mensalmente e algumas vezes por ano (repetitivas) admitem um efeito sobre aprendizagem que promove o controle. Isto se aplica não só a atividades meramente periódicas, mas também a alterações de configurações dos elementos recorrentes. Atividades não repetitivas são programas peculiares, investimentos ou campanhas.

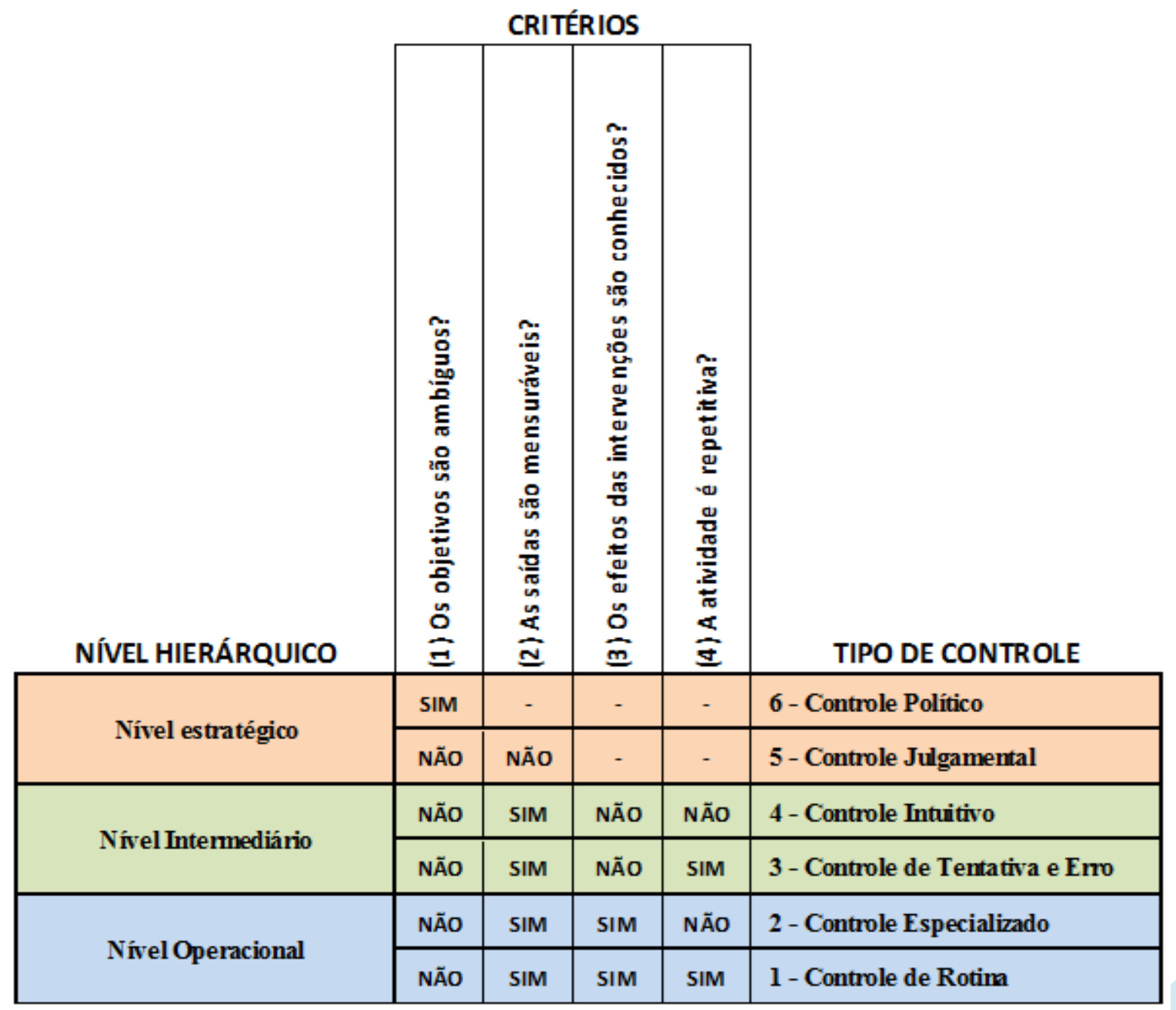

Figura 1 - Tipologia de decisão de controle em relação aos níveis hierárquicos Fonte: Elaborado pelos autores, baseado em Hofsted (1981) 


\section{Sustainable' Business \\ International Joumal}

SBIJ86 - JUNHO DE 2019 - ISSN 1807-5908

De modo a combinar os critérios para classificação de atividades, é necessário identificar os tipos de controle gerencial que seguem cada combinação e em qual nível hierárquico estes controles comumente podem ser encontrados. Existem 06 tipos de controle (Controle de rotina, Controle especializado, Controle de tentativa e erro, Controle intuitivo, Controle Julgamental e Controle político) que foram propostos por Hofstede (1981) de acordo com as respostas as alternativas mencionadas nos 04 critérios (perguntas) antes mencionados, do mais simples (Controle de rotina) ao mais complexo (Controle político).

\subsubsection{A Abordagem de Anthony e Young}

Os analistas tendem a se concentrar em vários critérios, ao avaliar a qualidade de um sistema de controle gerencial. A ausência de um ou mais desses critérios, e indica que o sistema necessita ser redesenhado. Os critérios mais relevantes quanto à qualidade de um SCG é ser: (1) um sistema total, (2) congruente com as metas, (3) estruturado financeiramente, (4) padronizado e cronologicamente definido e (5) ser um sistema coordenado e integrado.

As organizações não vocacionadas ao lucro situam-se numa área cinzenta, por não ter como objetivo a lucratividade, o sucesso das operações dessas organizações pode ser medido pela quantidade e qualidade dos serviços prestados para a sociedade, ao invés de ser medido financeiramente. Essa é uma expedição de difícil mensuração, haja vista o caráter difuso do processo de decisão e da carência de informações. 


\section{Sustainable Business \\ International Journal}

SBIJ86 - JUNHO DE 2019 - ISSN 1807-5908

As organizações sem fins lucrativos se distinguem em: (1) Organizações públicas governamentais, onde o controle realizado pela burocracia estatal está dividido de acordo com as instâncias governamentais (federal, estadual e municipal) contando com suas autoridades, agências e comissões. (2) Organizações privadas sem fins lucrativos: organizações voltadas para a caridade e organizações de associação de classe comerciais.

Dentre as características das organizações sem fins lucrativos que mais comprometem o processo do controle de gestão, destaca-se a falta de uma medida de lucro como a mais importante, as demais características também afetam, porém em níveis variados e não são exclusivas de organizações sem fins lucrativos, portanto, são tendências em vez de características difusas. Anthony e Young (2003) descrevem 08 características das organizações sem fins lucrativos:

1 - A ausência de uma medida de lucro;

2 - Considerações tributárias e legais diferentes;

3 - Uma tendência para serem organizações de serviços;

4 - Maiores restrições em metas e estratégias;

5 - Menos dependência de clientes para suporte financeiro;

6 - Domínio dos profissionais;

7 - Importância das influências políticas;

8 - Tradição de controles de gestão inadequados.

Um orçamento é um plano expresso em termos monetários. Existem essencialmente três tipos de orçamento: (1) o orçamento de capital, que lista e delineia as aquisições de capital planejadas, (2) o orçamento de caixa, que sintetiza os recebimentos e desembolsos planejados e (3) o orçamento operacional, que descreve as atividades operacionais 


\section{Sustainable Business \\ International Joumal}

SBIJ86 - JUNHO DE 2019 - ISSN 1807-5908

planejadas. Em organizações governamentais e outras organizações sem fins lucrativos, atualmente existem dois estágios para os orçamentos: $\mathrm{O}$ orçamento legislativo que é essencialmente um pedido de fundos, não correspondendo ao orçamento que é preparado em uma empresa com fins lucrativos onde sua a similaridade mais próxima é o prospecto que uma empresa prepara quando busca levantar dinheiro e o orçamento de gestão que é preparado após a legislatura ter decidido sobre o montante de fundos a ser provido, assim que o poder executivo faça uma boa estimativa do que o poder legislativo eventualmente vai aprovar (Anthony \& Young, 2003).

\section{CARACTERÍSTICAS DAS INSTITUIÇÕES DE SAÚDE PÚBLICA BRASILEIRA}

A execução orçamentária federal brasileira no ano de 2017 ficou em R\$ 2,39 trilhões, onde $\mathrm{R} \$ 1,26$ trilhão foi aplicado para o pagamento de encargos da dívida pública e o restante de $\mathrm{R}$ \$ 1,13 trilhão efetivamente destinado às áreas de atuações (funções) do governo federal. Dentre os recursos destinados à função governamental, a função "Saúde" ficou em segundo lugar consumindo o montante de $9,06 \%$ dentre os dispêndios destinados às funções governamentais, atrás apenas da função "Previdência social" que ficou em primeiro lugar, consumindo 55,06\% de todas as quantias destinadas às despesas funcionais (DA UNIÃO, 2018).

As aplicações dos recursos federais destinados à saúde ocorrem através de transferências constitucionais obrigatórias para Estados e Municípios, diretamente por meio do Ministério da Saúde e indiretamente através da descentralização por meio das autarquias, fundações públicas e empresas públicas. 


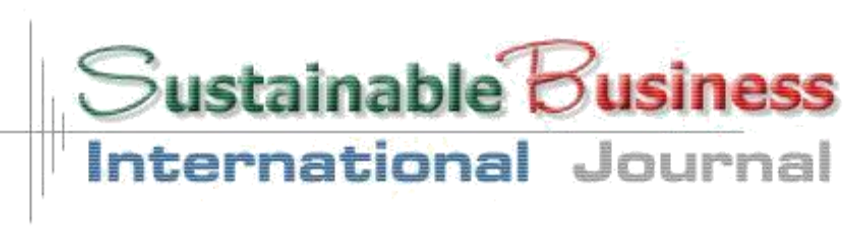

SBIJ86 - JUNHO DE 2019 - ISSN 1807-5908

O Sistema Único de Saúde (SUS) é complexo e a prestação de serviços na saúde pública do Brasil é efetuada de distintas formas, dentre as quais, o governo federal atuando diretamente ao ofertar para a sociedade serviços em saúde, através de entidades singulares dos órgãos do Ministério da Saúde e também através das organizações presentes na administração indireta. As empresas públicas devido as suas características de finalidade, controle contábil e de gestão de pessoal, não serão incluídas como objetos de pesquisas na proposição deste estudo.

\section{METODOLOGIA PROPOSTA}

Para identificar o nível de proximidade ou afastamento existente entre os sistemas de controles gerenciais utilizados pela instituição de saúde pública a ser pesquisada, junto ao encontrado na literatura que versa sobre o tema, recomenda-se a pesquisa do tipo qualitativa, que não se comprova através de números ou processos estatísticos, pois está relacionada com a necessidade do pesquisador em analisar, filtrar e interpretar os dados levantados e comparalos junto à teoria, com vistas a obter conclusões sobre o seu significado (Creswell, 2007).

Devido às características e as finalidades deste tipo pesquisa, indica-se adotar o método de estudo de casos, por permitir uma maior riqueza dos detalhes, admitindo um maior conhecimento sobre o assunto estudado. A pesquisa através de estudo de caso é frequentemente encarada, como uma forma menos desejável de investigação do que levantamentos ou experimentos devido a fornecer pouca base para generalização científica. No entanto, o estudo de caso permite uma investigação para se preservar as características holísticas e significativas dos eventos da vida real, tais como ciclos de vida 


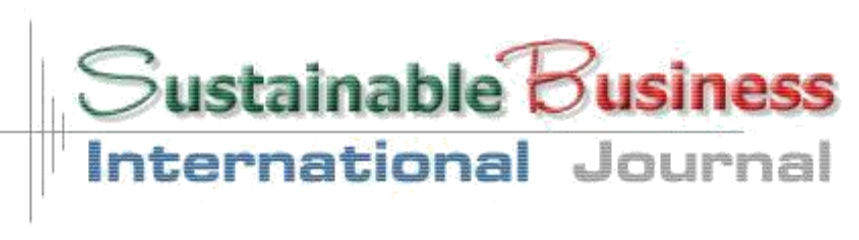

SBIJ86 - JUNHO DE 2019 - ISSN 1807-5908

individuais, processos organizacionais e administrativos, mudanças ocorridas em regiões urbanas, relações internacionais e a maturação de alguns setores (YIN, 2001).

Segundo Creswell (2007) os estudos de casos são utilizados como estratégias associadas à técnica qualitativa, em que o pesquisador explora em profundidade um programa, um fato, uma atividade, um processo ou uma ou mais pessoas. Tendo em vista que o objetivo desta pesquisa é uma proposição de estudos sobre as características do controle gerencial em organizações públicas unitárias em saúde, identificando, conhecendo os métodos utilizados por tais organizações, comparando e confrontando com a literatura disponível, levando em conta as especificidades da instituição.

Deste modo, concluímos que o estudo de caso pode mostrar-se como a técnica mais aconselhada, por ser aquela que possibilita alcançar um nível de profundidade pertinente sobre o objeto, permitindo um maior poder de análise através da comparação com tipologia ideal presente na literatura. Os diagnósticos da pesquisa visarão confrontar resultados alcançados, a fim de que se possa analisar e interpretar à luz do referencial teórico e se obter conclusões sobre o seu significado e colher mais informações sobre o assunto deste estudo.

A aplicação de questionários por meio de entrevista pessoal conduzida pelo pesquisador também facilita a sistematização das respostas, no caso de comparação com mais de uma organização. A utilização de um roteiro de entrevistas, sem o subsídio de um questionário como ferramenta, poderia se perder informações relevantes sobre o assunto, o que tornaria complicada uma posterior análise de dados. Outro motivo proeminente é que a utilização do questionário sem a presença do pesquisador não garantiria o nível desejado das questões e consequentemente uma correta interpretação por parte dos entrevistados, o que 


\section{Sustainable Business \\ International Journal}

SBIJ86 - JUNHO DE 2019 - ISSN 1807-5908

comprometeria a fidedignidade das respostas, bem como impossibilidade do controle exercido sobre a apresentação dos estímulos (perguntas) e das reações (respostas).

\section{MODELO OPERACIONAL PROPOSTO DE PESQUISA}

Para operacionalizar a pesquisa em Sistemas de Controle Gerencial em uma instituição de saúde pública, tendo em vista os objetivos do estudo e as características da administração pública brasileira, são propostas 05 variáveis que nortearão a pesquisa neste tipo de organização. Para atenuar problemas corriqueiros encontrados em trabalhos que utilizam o estudo de casos como método de pesquisa, a operacionalização destas variáveis, procura delimitar os comportamentos anotados ao longo das entrevistas de forma a confrontar com a referência teórica utilizada.

As variáveis componentes dos sistemas de controle gerencial (SCG) foram inspiradas nas pesquisas de Gomes e Martinewski (2007) em empresas estatais brasileiras. O foco desta pesquisa deve se concentrar em instituições públicas não vocacionadas para o lucro, por esse motivo, distinguem-se as variáveis propostas efetuadas em empresas estatais pelos autores antes citados.

Visando confrontar o caso que será estudado, com os temas definidos no referencial teórico, tendo em vista os recursos organizacionais utilizados pelas entidades públicas, as variáveis propostas dos sistemas de controle gerencial foram classificadas em:
a) Objetivos organizacionais
b) Processo de planejamento orçamentário
c) Processo de execução orçamentária
d) Medidas para avaliação de desempenho 


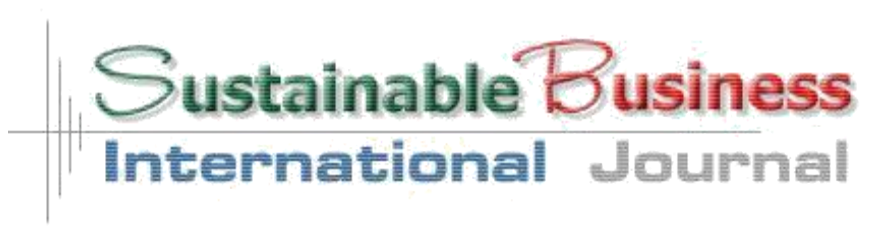

SBIJ86 - JUNHO DE 2019 - ISSN 1807-5908

e) Desenvolvimento dos sistemas de controle gerencial

\begin{tabular}{|c|c|c|c|c|}
\hline $\begin{array}{l}\text { COMPONENTE } \\
\text { VARIÁVEL DO } \\
\text { SCG }\end{array}$ & $\begin{array}{l}\text { ANÁLISE DA } \\
\text { VARIÁVEL }\end{array}$ & $\begin{array}{l}\text { REFERENCIAL } \\
\text { TEÓRICO }\end{array}$ & $\begin{array}{l}\text { Entidade } \\
\text { Pesquisada }\end{array}$ & $\begin{array}{l}\text { Documentos } \\
\text { Institucionais }\end{array}$ \\
\hline \multirow{4}{*}{$\begin{array}{l}\text { Objetivos } \\
\text { Organizacionais }\end{array}$} & $\begin{array}{l}\text { I - Avaliação da definição } \\
\text { e comunicação dos } \\
\text { objetivos à organização }\end{array}$ & $\begin{array}{l}\text { (Flamholtz, 1979; Gomes } \\
\text { \& Salas, 2001; Anthony } \\
\text { \& Young, 2003) }\end{array}$ & \multirow{4}{*}{$\begin{array}{l}\text { Entrevista } \\
\text { com gestor }\end{array}$} & \multirow{4}{*}{$\begin{array}{l}\text { Pesquisa } \\
\text { análise } \\
\text { documental }\end{array}$} \\
\hline & $\begin{array}{l}\text { II - Avaliação do } \\
\text { procedimento de mudanças } \\
\text { e revisão dos objetivos }\end{array}$ & $\begin{array}{l}\text { (Hofsted, 1981; Anthony } \\
\text { \& Young, 2003) }\end{array}$ & & \\
\hline & $\begin{array}{l}\text { III - Avaliação da } \\
\text { associação entre as metas e } \\
\text { objetivos }\end{array}$ & $\begin{array}{l}\text { (Lorange \& } \text { Morton, } \\
\text { 1974; Flamholtz, 1979; } \\
\text { Anthony \& Young, } \\
2003 ; \quad \text { Anthony \& } \\
\text { Gonvidarajan, 2008) }\end{array}$ & & \\
\hline & $\begin{array}{llr}\text { IV - } & \text { Verificação } & \text { de } \\
\text { avaliação de atendimento } & \text { de } \\
\text { dos } & \text { objetivos } & \text { da } \\
\text { organização } & \end{array}$ & $\begin{array}{l}\text { (Hofsted, 1981; Gomes } \\
\text { \& Salas, 2001; Anthony } \\
\text { \& Young, 2003) }\end{array}$ & & \\
\hline \multirow{3}{*}{$\begin{array}{l}\text { Planejamento } \\
\text { Orçamentário }\end{array}$} & $\begin{array}{lll}\text { I } \quad \text { Verificação da } & \text { dância conferida } \\
\text { importância } \\
\text { planejamento orçamentário }\end{array}$ & $\begin{array}{l}\text { (Hofsted, 1981; Anthony } \\
\text { \& Young, 2003) }\end{array}$ & \multirow{3}{*}{$\begin{array}{l}\text { Entrevista } \\
\text { com gestor }\end{array}$} & \multirow{3}{*}{$\begin{array}{l}\text { Pesquisa } \\
\text { análise } \\
\text { documental }\end{array}$} \\
\hline & 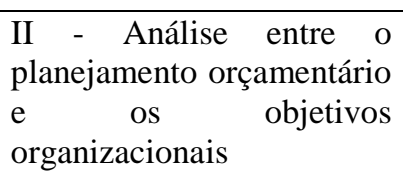 & $\begin{array}{l}\text { (Gomes e Salas, 2001; } \\
\text { Anthony e Young, 2003; } \\
\text { Pares e Valle, 2006) }\end{array}$ & & \\
\hline & $\begin{array}{l}\text { III - Avaliação do } \\
\text { planejamento orçamentário } \\
\text { quanto sua versatilidade e } \\
\text { adaptação } \text { a } \\
\text { externos }\end{array}$ & $\begin{array}{l}\text { (Hofsted, 1981; Anthony } \\
\text { e Young, 2003) }\end{array}$ & & \\
\hline \multirow{3}{*}{$\begin{array}{l}\text { Execução } \\
\text { Orçamentária }\end{array}$} & $\begin{array}{l}\text { I - Avaliação da execução } \\
\text { orçamentaria quanto sua } \\
\text { flexibilidade e adaptação a } \\
\text { fatores externos }\end{array}$ & $\begin{array}{l}\text { (Anthony ; Young, 2003; } \\
\text { Machado; } \quad \text { Holanda, } \\
2010)\end{array}$ & \multirow{3}{*}{$\begin{array}{l}\text { Entrevista } \\
\text { com gestor }\end{array}$} & \multirow{3}{*}{$\begin{array}{l}\text { Pesquisa } \\
\text { análise } \\
\text { documental }\end{array}$} \\
\hline & $\begin{array}{l}\text { II - Verificação de como se } \\
\text { dá a execução e controle } \\
\text { das despesas orçamentárias } \\
\text { mais importantes }\end{array}$ & $\begin{array}{lr}\text { Ribeiro } & \text { Filho et al, } \\
2008 ; & \text { Tridapalli } \\
\text { Fernandes; } & \text { Machado, } \\
2011) & \end{array}$ & & \\
\hline & $\begin{array}{l}\text { III - Análise de como as } \\
\text { despesas orçamentárias se } \\
\text { adequam aos objetivos } \\
\text { organizacionais }\end{array}$ & $\begin{array}{l}\text { (Anthony; Young, 2003; } \\
\text { Fernandes, 2008; Dos } \\
\text { Santos, 2014) }\end{array}$ & & \\
\hline
\end{tabular}




\section{Sustainable Business International Journal}

SBIJ86 - JUNHO DE 2019 - ISSN 1807-5908

\begin{tabular}{|c|c|c|c|c|}
\hline & $\begin{array}{l}\text { IV - Verificação da } \\
\text { importância } \\
\text { participação das pessoas } \\
\text { durante a execução } \\
\text { orçamentária }\end{array}$ & $\begin{array}{l}\text { (Flamholtz, 1979; } \\
\text { Hofsted, 1981; Gomes \& } \\
\text { Salas, 2001; Anthony \& } \\
\text { Young, 2003) }\end{array}$ & & \\
\hline \multirow{3}{*}{$\begin{array}{ll}\text { Avaliação } & \text { de } \\
\text { Desempenho } & \end{array}$} & $\begin{array}{l}\text { I - Verificação da } \\
\text { abrangência da finalidade, } \\
\text { dos procedimentos e das } \\
\text { medidas formais de } \\
\text { avaliação de desempenho } \\
\text { na instituição }\end{array}$ & $\begin{array}{l}\text { (Flamholtz, 1979; Gomes } \\
\text { \& Salas, 2001; Anthony } \\
\text { \& Young, 2003) }\end{array}$ & \multirow{3}{*}{$\begin{array}{l}\text { Entrevista } \\
\text { com gestor }\end{array}$} & \multirow{3}{*}{$\begin{array}{l}\text { Pesquisa } \\
\text { análise } \\
\text { documental }\end{array}$} \\
\hline & $\begin{array}{l}\text { II - Verificação da } \\
\text { legitimidade dos } \\
\text { procedimentos formais } \\
\text { utilizados no processo de } \\
\text { avaliação de desempenho }\end{array}$ & $\begin{array}{l}\text { (Hofsted, } \\
\text { Macintosh, } \\
\text { Anthony \& } \quad \text { 1981; } \\
\text { 2003) }\end{array}$ & & \\
\hline & $\begin{array}{ll}\text { III - Verificação } & \text { da } \\
\text { existência de programas de } \\
\text { desenvolvimento } & \text { de } \\
\text { pessoal de gestão } & \end{array}$ & $\begin{array}{l}\text { (Flamholtz, 1979; Gomes } \\
\text { \& Salas, 2001; Anthony } \\
\text { \& Young, 2003) }\end{array}$ & & \\
\hline \multirow{2}{*}{$\begin{array}{l}\text { Desenvolvimento } \\
\text { dos SCG }\end{array}$} & $\begin{array}{l}\text { I - Avaliação dos sistemas } \\
\text { de controle quanto a sua } \\
\text { flexibilidade e adaptação a } \\
\text { fatores externos }\end{array}$ & $\begin{array}{l}\text { (Anthony \& Young, } \\
\text { 2003; Ribeiro Filho et al, } \\
\text { 2008; Matos, 2010) }\end{array}$ & \multirow{2}{*}{$\begin{array}{l}\text { Entrevista } \\
\text { com gestor }\end{array}$} & \multirow{2}{*}{$\begin{array}{l}\text { Pesquisa } \\
\text { análise } \\
\text { documental }\end{array}$} \\
\hline & $\begin{array}{l}\text { II - Verificação dos } \\
\text { instrumentos de controle } \\
\text { gerencial utilizados pelas } \\
\text { unidades }\end{array}$ & $\begin{array}{l}\text { (Hofsted, 1981; Matos, } \\
\text { 2010; Frezatti et al., } \\
\text { 2012) }\end{array}$ & & \\
\hline
\end{tabular}

Quadro 1 - Desenho de pesquisa das variáveis dos sistemas de controle gerencial Fonte: Elaborado pelos autores.

Para analisar a variável 'objetivos organizacionais', almeja-se a obtenção de informações sobre os objetivos da entidade e de que forma eles são transmitidos. Compete ao pesquisador orientar ao entrevistado quais são os conceitos de: Objetivos gerais (tradução do planejamento estratégico em conformidade coma s diretrizes e políticas governamentais); Objetivos específicos (Desdobramento dos objetivos gerais, no espaço temporal superior a 01 ano) e; Metas (objetivos de curto prazo no espaço temporal inferior a 01 ano). Como exemplo de questões a serem abordadas no questionário, tais perguntas podem versar sobre: 


\section{Sustainable Business \\ International Journal}

SBIJ86 - JUNHO DE 2019 - ISSN 1807-5908

1. Como se estabelece e quais são os objetivos gerais da entidade;

2. A existência de documentos institucionais que abordem sobre os objetivos organizacionais;

3. Quais as funções e responsabilidades dos funcionários públicos que participam do estabelecimento dos objetivos da organização;

4. Como se desdobram os objetivos gerais, específicos e metas da organização e quais os atores organizacionais que participam desse processo.

5. De que modo se avaliam os resultados alcançados, em como se efetuam as revisões sobre os objetivos definidos e quais atores da organização participam destes processos.

6. Qual o processo formal ou não, que visem integrar o planejamento estratégico ou objetivo geral, com os objetivos de médios e curtos prazos.

A análise da variável do SCG 'Planejamento Orçamentário', deseja-se o alcance das informações sobre o desenvolvimento e a implantação do processo de planejamento do orçamento e de que forma eles são informados para os membros da organização. Como exemplo de questões a serem abordadas no questionário, tais perguntas podem versar sobre:

1. Quais são os principais propósitos do sistema de orçamento da entidade e seu grau de importação na formulação do planejamento;

2. Quem são os membros externos ou internos da organização que aprovam e elaboram a proposta orçamentária da entidade pesquisada;

3. As informações mais utilizadas na discussão e elaboração no início da estimativa orçamentária;

4. Quais as dificuldades encontradas para elaborar e aprovar o orçamento.

5. As informações mais utilizadas na aprovação final do orçamento; 


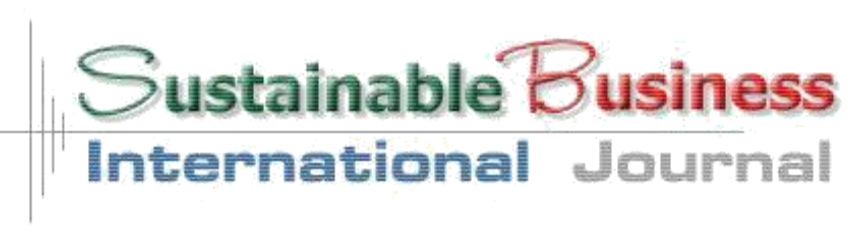

SBIJ86 - JUNHO DE 2019 - ISSN 1807-5908

Sobre analisar a variável do SCG 'Execução Orçamentária', se espera obter informações sobre o desenvolvimento e a implantação do processo de execução orçamentária e de que modo eles são comunicados para os membros da organização. Como exemplo de questões a serem abordadas no questionário, tais perguntas podem versar sobre:

1. Como se inicia o período da execução orçamentária definido no planejamento

2. Como e qual a periodicidade que a execução orçamentária aprovada é monitorada ou examinada, e quem são os membros da organização pesquisada responsáveis por esta tarefa.

3. A existência de documentos institucionais ou sistemas informatizados que formalizem ou avaliem o monitoramento da execução orçamentária;

4. Quais são as despesas orçamentárias mais relevantes para a organização pesquisada e como estes dispêndios são acompanhados pelos membros e pela alta gestão da organização.

5. Quais as funções e responsabilidades dos funcionários públicos que participam da gestão da execução orçamentária;

6. Qual o grau de comprometimento dos atores envolvidos na execução do orçamento, quanto ao alcance das metas estabelecidas durante o planejamento orçamentário.

Para analisar a variável 'Avaliação de desempenho', se deseja a obtenção de informações sobre a validade de instrumento formal de avaliação do desempenho dos membros da organização, quanto ao alcance dos objetivos organizacionais. Também se busca conhecer como a organização aperfeiçoa ou capacita o seu pessoal, para o desenvolvimento de suas atividades. Como exemplo de questões a serem abordadas no questionário, tais perguntas podem versar sobre: 


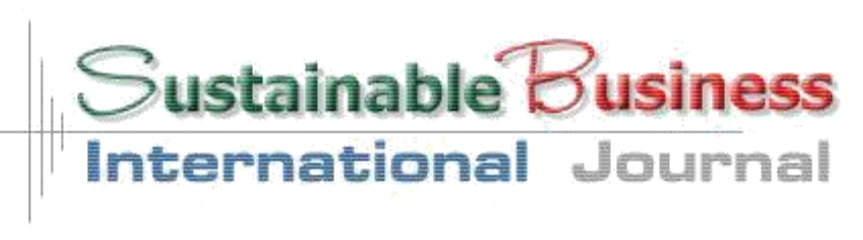

SBIJ86 - JUNHO DE 2019 - ISSN 1807-5908

1. Como se percebe a influência dos membros da organização, em todos os níveis, quanto ao alcance das metas orçamentárias estabelecidas;

2. Qual a política institucional adotada pela organização, quanto aos profissionais envolvidos diretamente no planejamento e execução orçamentária para o alcance dos objetivos organizacionais;

3. Qual o comprometimento dos atores organizacionais quanto ao alcance das metas orçamentárias estabelecidas;

4. A existência de algum programa institucional de educação ou aperfeiçoamento continuado dos membros da organização que atuam diretamente no planejamento e execução orçamentária;

5. Qual a importância considerada pela alta gestão da organização, quanto à capacitação do seu corpo funcional e quais os resultados esperados ou alcançados após esse processo de aperfeiçoamento profissional.

Por fim a análise da variável do SCG 'Desenvolvimento dos sistemas de controle gerencial', deseja-se o alcance das informações sobre os instrumentos, meios e mecanismos utilizados para auxiliar o processo de controle gerencial, bem como a evolução destes artefatos de gestão dentro do contexto organizacional da entidade a ser pesquisada. Como exemplo de questões a serem abordadas no questionário, tais perguntas podem versar sobre:

1. Como é feito o controle gerencial na organização e se existem sistemas informatizados que auxiliem neste controle. 


\section{Sustainable Business \\ International Joumal}

SBIJ86 - JUNHO DE 2019 - ISSN 1807-5908

2. Quais os instrumentos, meios e mecanismos desenvolvidos pela organização no auxílio da gestão estratégica, tática e operacional e se existem sistemas informatizados que auxiliem nesta gestão;

3. Como os sistemas governamentais existentes auxiliam no controle gerencial da organização pesquisada;

4. Qual o nível de conhecimento e quais são os artefatos de controle gerencial que são utilizados pela entidade a ser pesquisada;

\section{CONSIDERAÇÕES FINAIS}

O objetivo deste artigo foi propor uma operacionalização para pesquisas em sistemas de controle gerencial nas organizações singulares dentro sistema de saúde pública brasileira. A análise dos SCG deve ser em entidades individuais, por exemplo, dentro do sistema de saúde, limitando-se a um instituto de pesquisa, uma clínica, um hospital ou um laboratório, visando entender como funciona os seus sistemas de controle gerencial. A metodologia proposta foi o método de estudo de caso, que através de entrevistas pessoais, deve ser complementado por dados secundários obtidos em informações constantes em sites oficiais da organização, relatórios de gestão e de auditoria e outros documentos institucionais que possibilite uma análise sobre os recursos organizacionais.

A primeira variável "Objetivos organizacionais", visa analisar e verificar a estratégia seguida pela instituição pesquisada. Devido ao objetivo precípuo da entidade pública em prestar serviços de saúde aos seus cidadãos, cabe verificar se a estratégia organizacional da entidade pesquisada está coadunada aos objetivos organizacionais. 


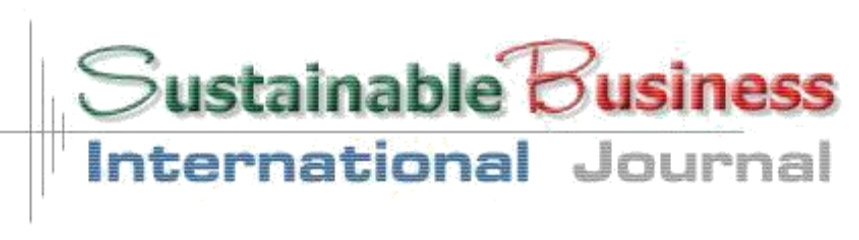

SBIJ86 - JUNHO DE 2019 - ISSN 1807-5908

O recurso financeiro é o ponto de convergência para analisar as atividades desenvolvidas pelos entes públicos, deste modo o orçamento assume o papel principal em qualquer análise financeira, dessa forma a variável planejamento orçamentário e execução orçamentária apresentam importância primária para os sistemas de controle gerencial em instituições públicas.

No processo de planejamento orçamentário, a análise desta variável do sistema de controle gerencial tem objetiva avaliar o ajustamento das metas da organização ao seu sistema de planejamento e controle do orçamento. Quanto ao processo de execução orçamentária objetiva avaliar a como a organização a ser pesquisada executa e controla suas despesas orçamentárias e se há adequação junto às metas definidas em seus objetivos organizacionais.

Os sistemas de controle gerencial devem incentivar a harmonia das metas organizacionais e metas individuais dos membros da organização e a congruência desses objetivos pode ser analisada através da variável "Medidas de avaliação de desempenho". Esta variável tem por objetivo analisar e aferir a existência e a validade de instrumentos formais de avaliação de desempenho, a fim de manter comportamentos positivos e ajustar desvios quanto ao alcance de objetivos de toda organização.

Para verificar como as estruturas de controle se adaptam ao meio ambiente, e como se dá a sua evolução ao longo do tempo na organização a ser estudada, temos a variável "Desenvolvimento dos sistemas de controle gerencial" para obter tais respostas. Esta variável do SCG ao ser analisada, objetiva avaliar o progresso do SCG da instituição, examinando sua adequabilidade aos mecanismos distintos de controle em relação ao ambiente exterior. Também objetiva conseguir informações sobre as técnicas de gestão utilizadas. 


\section{Sustainable Business \\ International Journal}

SBIJ86 - JUNHO DE 2019 - ISSN 1807-5908

Foram apresentados modelos de questões que poderão nortear os futuros questionários, que devem ser baseados em cada uma das variáveis propostas, os quais auxiliarão o pesquisador em posterior coleta e análise dos dados, para confrontá-los com os achados encontrados na literatura, podendo ser complementados com outras perguntas, caso o pesquisador julgue necessário.

As variáveis de pesquisa propostas colaborarão para um melhor conhecimento sobre sistemas de controle gerencial no setor de saúde pública e para futuros estudos sobre o tema, ao permitir a comparabilidade dos resultados alcançados com o encontrado no referencial teórico sobre controle gerencial em organizações públicas, em especial sobre os recursos organizacionais utilizados por estas organizações.

Recomenda-se, a adoção de outras variáveis, além das consideradas neste estudo, tais como, cultura organizacional, internacionalização, tecnologia, capital intelectual, dentre outras variáveis que possam auxiliar o atendimento de objetivos específicos de pesquisas voltadas para os sistemas de controle gerencial em instituições de saúde pública não vocacionadas ao lucro, inclusive nas administrações diretas e indiretas dentro de todas as esferas de governo do Brasil.

\section{REFERÊNCIAS}

ANTHONY, Robert N., YOUNG, David W. Management Control in Nonprofit Organizations. New York, McGraw Hill, 2003. 2008. ; GOVIDARAJAN, Vijay. Sistemas de controle gerencial. 12.ed. São Paulo: Saraiva,

DO BRASIL, Senado Federal. Constituição da república federativa do Brasil. Brasília: Senado Federal, Centro Gráfico, 1988. Disponível em: http://www.planalto.gov.br/ccivil_03/constituicao/constituicaocompilado.htm Acesso em 17 mar. 2018. 


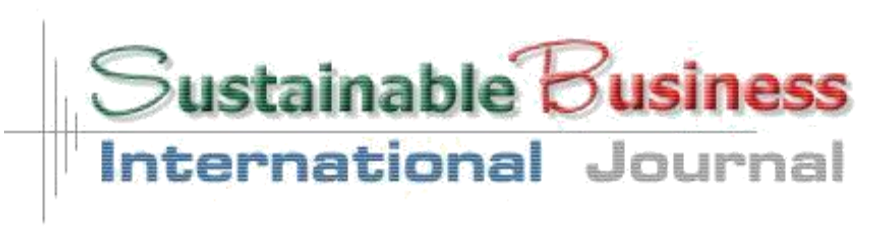

SBIJ86 - JUNHO DE 2019 - ISSN 1807-5908

CRESWELL, J. W. Projeto de pesquisa: métodos qualitativo, quantitativo e misto. 2. ed. Porto Alegre: Artmed, 2007.

FERNANDES, Ciro Campos Christo. A organização da área de compras e contratações públicas na administração pública federal brasileira: o elo frágil. Revista do Serviço Público, v. 67, n. 3, p. 407-432, 2016.

FLAMHOLTZ, Eric. Organizational control systems as a managerial tool. California management review, v. 22, n. 2, p. 50-59, 1979.

GOMES, Josir Simeone; MARTINEWSKI, André Luiz. O impacto da reforma do estado sobre os sistemas de controle gerencial em empresas brasileiras durante o período de 1983 a 2003: estudo de nove casos. RIC-Revista de Informação Contábil, v.1, n.1, p. 31-48, 2007.

GRATERON, Ivan Ricardo Guevara. Auditoria de gestão: utilização de indicadores de gestão no setor público. Caderno de estudos, n. 21, p. 01-18, 1999.

HOFSTEDE, Geert. Management control of public and not-for-profit activities. Accounting, Organizations and society, v. 6, n. 3, p. 193-211, 1981.

MACHADO, Nelson; HOLANDA, Victor Branco de. Diretrizes e modelo conceitual de custos para o setor público a partir da experiência no governo federal do Brasil. Revista de Administração Pública, v. 44, n. 4, p. 791-820, 2010.

MACINTOSH, Norman B. Management Accounting and Control Systems: An Organizational and Behavioral Approach. 1994.

OTLEY, David. Management control in contemporary organizations: towards a wider framework. Management accounting research, v. 5, n. 3-4, p. 289-299, 1994.

PARES, Ariel; VALLE, Beatrice. A retomada do planejamento governamental no Brasil e seus desafios. Coletânea Planejamento e orçamento governamental, v. 1, 2006.

PELLINI, Ana Maria. Os Sistemas de Planejamento, Execução e Controle da Gestão PúblicaUma Nova Proposta. ConTexto, v. 3, n. 4, 2008.

PINTO, Élida Graziane. Discricionariedade, contingenciamento e controle orçamentário. Revista Gestão \& Tecnologia, v. 6, n. 2, 2006.

QUINTAL, Renato Santiago et al. Uma reflexão sobre a aplicação do controle gerencial ao setor público brasileiro durante os últimos 20 anos. Revista Uniabeu, v. 5, n. 10, p. 263-273, 2012.

RIBEIRO FILHO, José Francisco et al. Controle interno, controle externo e controle social: análise comparativa da percepção dos profissionais de controle interno de entidades das três esferas da administração pública. Revista Universo Contábil, v. 4, n. 3, p. 48-63, 2008.

SANCHES, Osvaldo Maldonado. Processo orçamentário federal: problemas, causas e indicativos de solução. Revista de Administração Pública, v. 29, n. 3, p. 122-156, 1995.

DOS SANTOS, Alberto Almeida. Gestão da Contratualização no Setor Público Brasileiro: Proposta de Diretrizes. Sistemas \& Gestão, v. 9, n. 3, p. 328-339, 2014. 


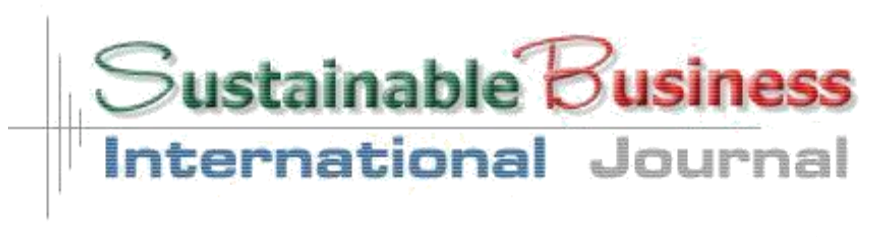

SBIJ86 - JUNHO DE 2019 - ISSN 1807-5908

TRIDAPALLI, Juarez Paulo; FERNANDES, Elton; MACHADO, Waltair Vieira. Gestão da cadeia de suprimento do setor público: uma alternativa para controle de gastos correntes no Brasil. Rev. Adm. Pública, Rio de Janeiro, v. 45, n. 2, p. 401-433, Abr. 2011.

DA UNIÃO, M.T. C. G. (2018). Portal da transparência. Orçamento anual. Disponível em: < http://www.portaltransparencia.gov.br/orcamento>. Acesso em 07 mar. 2018.

VAZ, José Carlos; LOTTA, Gabriela Spanghero. A contribuição da logística integrada às decisões de gestão das políticas públicas no Brasil. Revista de Administração Pública, v. 45, n. 1, p. 107-139, 2011. 